\title{
UMA EXPERIÊNCIA ENTRE LÍNGUAS: TRADUZINDO ENRICO TESTA
}

\author{
Patricia Peterle
}

Resumo: Pensar a tradução como um perpassar e vivenciar por duas (ou mais) línguas significa mergulhar no vórtice que esse próprio ato produz. Traduzir - como teóricos, poetas e escritores já colocaram, dentre eles Italo Calvino - é o melhor modo de se ler um texto, pois o tradutor não tem o álibi do leitor comum, que pula as partes mais elípticas sem grandes preocupações. Refletir sobre um texto, por meio dessa confluência, significa escolher instrumentos e potências para adentrar, penetrar e fazer (per)viver o corpo e a voz do poema - mesmo que com alguns desvios. Nessa perspectiva, entende-se o gesto de tradução como um acontecimento no espaço do "entre", uma experiência que se dá na-da-pela-língua e, portanto, um lugar de alteridades e de eticidade. A discussão será proposta através da tradução de um recente poema de Enrico Testa, uma das vozes mais representativas da poesia italiana contemporânea, publicado no volume Cairn, em 2018. Palavras-chave: traduzir; Enrico Testa; poesia italiana.

"O escrever em versos [...] parece-nos [...] um sopro
sobre a cinza para que se transforme em brasas -
assumida com toda a comunidade: seja a dos que são,
como dos que foram, e dos que serão."

(E. Testa)

"Da mesma forma como os cacos de um vaso, para serem recompostos, devem seguir-se uns aos outros nos mínimos detalhes, mas sem serem iguais, a tradução deve, ao invés de procurar assemelhar-se ao sentido original, conformar-se cuidadosamente, e nos mínimos detalhes, em sua própria língua [...] como cacos são fragmentos de um vaso.”

(W. Benjamin)

1 Departamento de Língua e Literatura Estrangeiras e dos Programas de Pós-Graduação em Literatura e Estudos da Tradução da Universidade Federal de Santa Catarina(UFSC): $<$ patriciapeterle@gmail.com>. 
É verdade que nos últimos anos o campo dos estudos da tradução teve, dentro da academia, e não só no Brasil, um crescimento a olhos vistos, que vem produzindo reflexões importantes e experiências em nível de graduação e pós-graduação igualmente significativas. Em medida parecida, também é verdade que o mercado editorial, relativo a livros traduzidos, apesar da crise, tem apresentado números não desprezíveis, e as pequenas editoras têm tido um papel importante na publicação de novos autores ou de traduções de livros célebres que até então eram inéditos por aqui.

Entretanto, todo esse alargamento, sem dúvida marcado por expansões, não torna mais fácil o árduo ato de traduzir. Com efeito, propor a tradução de um texto não é tarefa fácil. A expressão "estou traduzindo o texto X" carrega consigo uma série de questões inerentes e latentes, que poderiam ser sintetizadas nos seguintes pontos: 1) problemáticas referentes ao próprio texto; 2) especificidades identificadas no uso da língua em que o texto se apresenta; 3) questões culturais que muitas vezes se escondem em certas expressões e modos de dizer; 4) relação entre as línguas envolvidas; 5) relação do tradutor com essas duas línguas envolvidas; 6) o modo como se dá a ocupação do espaço do enunciado "estou traduzindo"; 7) a forma como esse "eu-tradutor" se coloca perante o texto a ser traduzido; 8) o modo como esse mesmo "eu-tradutor" aciona sua língua, e o uso que faz dela e da cultura que carrega consigo. Esses são apenas alguns pontos, nada simples, que se desdobram em outros, pois a tarefa do tradutor é da ordem do complexo.

É uma experiência que se faz na-da língua pela língua (evocar essas preposições, aqui, é fundamental) e, portanto, é uma relação que exige a presença do outro. É, enfim, uma experiência singular-plural, pois necessita da presença de outrem na mesma medida em que demanda uma especificidade mais íntima, que só pode vir da esfera do eu. Nesse sentido, se o autor trabalha com a linguagem suspendendo seu uso mais habitual, se quisermos funcional, para encontrar um novo uso, o tradutor terá de mergulhar nesse espaço perfilado de porosidades. ${ }^{2}$ Por isso, apesar de a tradução ser um ato de assombramento, como afirma Marcelo Jacques (2017, p. 225), também "é algo reconfortante saber que a escrita tem no

\footnotetext{
2 O conceito de porosidade em relação ao poético foi trabalhado na disciplina "Pensamento e Poesia: porosidades e sensações”, oferecida por mim no segundo semestre de 2016, no Programa de Pós-Graduação em Literatura (PPGLIT) da Universidade Federal de Santa Catarina (UFSC).
} 
empreendimento tradutório, um roteiro pré-traçado, um volume pré-definido", por mais que as dobras desse ato não deixem de trazer à luz crateras e buracos negros presentes no "roteiro".

Em termos de tradução poética, que é o que nos interessa, se pensarmos num moto espiralar, a intensidade é ainda maior, uma vez que a poesia não afirma um regime de precisão, mas afirma um acesso (NANCY, 2016, p. 150). A reflexão de tal consideração pode contribuir para essa tarefa, que exige do tradutor deslocamentos nas-das-pelas línguas em que transita. Se, retomando Nancy (p. 151), "o poema é a coisa feita do fazer ele mesmo" e "poesia é fazer tudo falar", os fantasmas e os impasses não param de bater à porta do tradutor. Como lidar com toda uma tradição evocada por meio de palavras, que podem parecer as mais simples e até banais, mas na verdade estão imbuídas de uma série de tensões? Walter Benjamin e Giorgio Caproni, a esse respeito, em dois textos dedicados à tradução, propõem uma reflexão a partir de um binômio: Brot e pain, para o primeiro, e Brot e pane, para o segundo.

Benjamin (2010, p. 213), em "A tarefa do tradutor", de 1923, resultado dos embates travados com os Tableaux parisiens de Baudelaire, afirma:

Em "Brot" e "pain" o visado é o mesmo; mas o modo de visar, ao contrário, não o é. Está implícito, pois, no modo de visar, o fato de que ambas as palavras significam algo diferente para um alemão e um francês, respectivamente; que, para eles, elas não são intercambiáveis e que, aliás, em última instância, almejem excluir-se mutuamente; quanto ao objeto visado, porém, tomadas em termos absolutos, elas significam a mesma e idêntica coisa.

Caproni (2016, p. 238), em "Pão e Bread", de 1949, texto dedicado à traduzibilidade e intraduzibilidade da poesia, entra na questão colocada por Benjamin ao dizer que a experiência que se possui do objeto (pão) é a mesma. Sendo ele poeta, sua reflexão vai ainda mais longe, para além da questão referencial e cultural (o visado e o modo de visar), no momento em que atribui à palavra poética outras nuances e dobras, fios tecidos dentro de uma língua e de uma experiência feita na-da língua.

Assim, em poesia, uma palavra assume, além de seu significado lexical, um imprevisível número de significados que eu gostaria de comparar aos "harmônicos" de uma nota musical, e todos despontados não somente do valor da palavra em si, mas junto com o lugar que ela ocupa na tessitura harmônica do poema. (CAPRONI, 2016, p. 238)

Num outro texto de 1973, "Divagações sobre traduzir", conferência proferida por ocasião do prêmio Monselice, que lhe foi atribuído pela 
tradução de Il n’y a pas de paradis, de André Frenaud, Caproni (2016, pp. 257-258) retoma essa mesma questão:

\begin{abstract}
Vou me limitar a repetir que, em primeiro lugar, somente um ouvido finíssimo, junto com um perfeito conhecimento filológico das duas línguas e com um perfeito conhecimento histórico e sociológico das duas diferentes culturas, poderá socorrer o tradutor ao procurar salvar (talvez, sem sintonia) o sentido literal sem destruir as vibrações da poesia, mas sempre com a condição - e este é o ponto - de não esquecer um só instante de si mesmo. Ele deve cunhar em seu próprio laboratório a dupla moeda da sua palavra e da palavra dos outros, para retirar do som uma série de harmônicos diferentes (os significados harmônicos de bread, por exemplo, certamente não são os mesmos dos de um pão (pane) muito católico, e isso não somente no plano musical, como já escrevi mais de trinta anos atrás), mas de maneira que possam ser aproximados quanto mais possível ao valor original.
\end{abstract}

De que forma a palavra vibra? Essa talvez seja a questão transversal a Benjamin e Caproni, e aqui o tradutor tem um árduo fardo que é o de encontrar a "mesma" (sempre outra) vibração, sem esquecer da sua voz (de si mesmo). É interessante perceber, sendo Caproni poeta-tradutor, como há uma tensão entre o início e o final desse fragmento. As condições que podem socorrer o tradutor, "perfeito conhecimento filológico das duas línguas e com um perfeito conhecimento histórico e sociológico das duas diferentes culturas" (CAPRONI, 2016, p. 257) - por meio do termo escolhido "perfeito" -, estão fadadas em certos momentos ao insucesso, falência e luto. Talvez por isso, tenha-se na última linha o uso de "aproximados", mas nunca uma cópia, um simulacro do original. A aproximação pode implicar movimentos de "deformação", ela é fruto da renúncia ao ideal da tradução perfeita, da fidelidade, da impossibilidade de servir a dois patrões (RICOEUR, 2011, p. 27). Ao tradutor não cabe encontrar uma forma fixa, mas sim "cunhar em seu laboratório a dupla moeda da sua palavra e da palavra dos outros” (CAPRONI, 2016, p. 257), moeda que será, por sua vez sempre igual e sempre diferente. O gesto tradutório se mostra, assim, como uma resistência ao pensamento hegemônico, privilegiando a relação entre as línguas: partilhas. E aponta, ao mesmo tempo, para as singularidades das línguas, para essa eterna complexidade que não deve ser apagada, desconsiderada, aniquilada, e que é a vida da tradução, uma demanda pelo outro - ou melhor, pela relação com o outro.

Se escrever, para lembrar Deleuze (1997), não é a imposição de uma forma, mas é a exposição da potencialidade da matéria vivida - e daí o inacabado e o informe como traços inseparáveis do devir inerente à escrita -, a tradução pode ser pensada também como uma exposição 
de potencialidades, um devir sempre outro. Nesse sentido, retomando mais uma vez Walter Benjamin (2012, pp. 207-209), não podemos considerar as traduções simplesmente como transmissões, mas sim como inserções num laboratório em que a "vida do original alcança, de maneira constantemente renovada, seu mais tardio e mais vasto desdobramento". É, justamente, esse desdobrar que faz com que o original tenha uma sobrevida, que a tradução faça parte desta e seja um elemento essencial da pervivência, ${ }^{3}$ sendo ela "uma forma, de algum modo provisória, de lidar com a estranheza das línguas" (BENJAMIN, 2012, p. 216). O elemento de estranhamento é, assim, essencial por ser um indício e ressaltar a própria alteridade. Nesse laboratório, é preciso "encontrar na língua para a qual se traduz a intensão a partir da qual o eco do original é nela despertado" (p. 217); eco que não pode findar no "visado" e que traz consigo harmônicos e vibrações que também ecoam. O silêncio é silêncio da própria palavra, seu tornar-se invisível, pois somente ela - a palavra - nos coloca em contato com as coisas mudas (AGAMBEN, 1999, p. 112).

Ecos, ecososososos $e^{o s} \mathrm{C}^{\text {os }} \mathrm{o}^{\text {os }} \mathrm{s}^{\text {os }}$ que, na relação entre línguas, vão ganhando forma na medida em que os sons se misturam no corpo "material" de uma espécie de espiral.

Cabe refletir sobre o especial estatuto de singularidade que define o vórtice: ele é uma forma que se separou do fluxo da água do qual fazia parte, e ainda faz, de algum modo; é uma região autônoma e fechada em si mesma e obedece a leis que lhe são próprias; contudo, está estreitamente ligada à totalidade em que está imersa, é feita da mesma matéria, que troca continuamente com a massa líquida que a cerca. É um ser à parte e, mesmo assim, não há uma gota que de fato lhe pertença, sua identidade é absolutamente imaterial. (AGAMBEN, 2018, p. 84)

Essa poderia ser uma imagem para se pensar o mergulho que é o ato de traduzir. Ou seja, a entrada nesse redemoinho, cujo movimento puxa e suga para seu interior, em cujas entranhas há uma voracidade quase vertiginosa, com a suspensão dos fluxos regulares das línguas. Contudo, de fora - não tão ao longe -, a mesma imagem do vórtice pode parecer ter outras conotações, talvez até mais compassadas. É justamente essa complementariedade, ao lado das demais já mencionadas, que atua eopera

3 O termo usado por Walter Benjamin é Fortleben, que significa continuação da vida. Na sua tradução, Susana Kampf Lages recorre ao neologismo de Haroldo de Campos, "pervivência”, para dar conta da polissemia presente na língua alemã e para manter o jogo de forma e sentido entre Leben, vida, Überleben, sobrevivência, Fortleben, "pervivência". 
de forma mais ou menos silenciosa no (des)encontro desempenhado pela relação que vai se delineando através do ato de uma tradução, que exige experiências entre línguas. Assim, traduzir é (re)ler, é (re)pensar o texto, é ser, de algum modo, tocado pelo fluxo contido no texto a ser traduzido. Ao mesmo tempo em que o tradutor é afetado - portanto, uma ação de aproximação - ele precisa de certa distância para "entender o original", conforme aponta Walter Benjamin (2012, pp. 217-219), ao retomar a vizinhança existente entre tradução e crítica por meio dos românticos alemães. Por isso o ato tradutório é, por necessidade, anacrônico e só se dá por meio das tensões que se constituem e são geradas e ativadas pela leitura, que é o estabelecimento de um contato. A tradução como transmissão de sentido está fadada ao insucesso, porque, nessa perspectiva, ao eleger aquele que predomina, ela desconsidera a tensão gerada pela presença do outro. A predileção por uma parte hegemônica requer o apaziguamento, o esgarçamento das tensões e do espaço poroso entre as línguas, que é o mais rico, o mais precioso (por suas não certezas). Não há uma abertura para a eticidade, quando a possibilidade de relações é suprimida. É, exatamente, por isso que Antoine Berman (2007) enfatiza o fato de não poder haver um espaço definido e valores próprios, sendo a existência da esfera do babélico uma exigência. ${ }^{4}$

Numa entrevista de 1980, concedida a Tullio Pericoli, Italo Calvino (2002) trata da figura do tradutor como a de um leitor especial. Para ele trata-se de uma leitura que exige pensar nas redes potenciais de cada palavra, pois a tradução é uma intensidade de leitura. Dois anos depois, numa conferência proferida em Roma, Calvino, que já trabalhava como editor na Einaudi eque, em 1967, havia passado pela imbricada experiência de traduzir Les fleurs bleus de Raymond Queneau, nessa mesma linha afirma:

Quem escreve numa língua minoritária como o italiano chega mais cedo ou mais tarde à amarga constatação que a sua possibilidade de comunicar se sustenta sobre fios finos como teia de aranha: basta mudar o som e a ordem e o ritmo das palavras para que a comunicação falhe. Quantas vezes lendo o rascunho de um texto meu que o tradutor me mostrava, me dava uma estranha sensação de estranhamento quanto àquilo que lia; estava ali tudo que eu tinha escrito? Como tinha podido ser tão chato e insípido? Depois indo

4 Nesse sentido, faz-se referência à exposição, com curadoria de Barbara Cassim, Après Babel, realizada em 2016, no Musée des civilisations de L'Europe et de la Méditerranée, na cidade de Marselha. Disponível em: <http://www.mucem.org/programme/exposition-ettemps-forts/apres-babel-traduire >. Acesso em: 16 set. 2018. 
reler o meu texto em italiano e confrontando com a tradução via que era uma tradução até muito fiel, mas no meu texto uma palavra era usada com uma intenção irônica só insinuada que a tradução não captava, uma subordinada no meu texto era muito leve enquanto na tradução tomava uma importância injustificada e um peso desproporcional; o significado de um verbo no meu texto era esfumado pela construção sintática da frase enquanto na tradução soava como uma afirmação peremptória: em resumo a tradução comunicava uma coisa completamente diferente do que eu tinha escrito. (CALVINO apud MENEGHELLO, 2011, Anexo 2,5 p. 83) ${ }^{6}$

Ler, portanto, significa aqui penetrar nas entranhas do texto para captar seus movimentos mais recônditos, o título da citada conferência, então, não poderia deixar de ser "Traduzir é o melhor modo para se ler um texto". Calvino toca num aspecto sensível, a questão da fidelidade, que, como ele mesmo aponta, pode se apresentar como seu reverso, ou seja, como uma traição. Traduzir é arriscar-se, é sobretudo um desafio; é ter a consciência de que a queda está sempre próxima e que o abismo está à espera - sem portas ou guardiões. As tesselas do mosaico da língua, na relação entre línguas, não podem sempre ocupar o mesmo espaço, pois as tensões e os jogos de força não se espelham, isso só acontecerá se pensarmos num espelho que distorce a figura refletida: sempre a mesma e sempre diferente. A imagem que o mosaico gera por meio da organização cuidadosa e atenta de suas inúmeras tesselas (que deve levar em consideração um "roteiro", para retomar Marcelo Jacques, cheio de

5 Para a tradução deste e de outros textos de Italo Calvino relacionados à tradução, faz-se referência ao trabalho de mestrado Italo Calvino: um ponto de vista sobre o papel da tradução literária (UFSC/PGET, 2011), e doutorado, Italo Calvino e o intricado jogo da tradução (UFSC/PGET, 2016), de Helena Coimbra Meneghello. No caso da citação acima, trata-se do trabalho de mestrado, Anexo 2, p. 83. Disponível em: <https://repositorio.ufsc. $\mathrm{br} /$ bitstream/handle/123456789/9479o/296716.pdf? sequence=1>. Acesso em: 10 abr. 2018. 6 "Chi scrive in una lingua minoritaria come l'italiano arriva prima o poi all'amara constatazione che la sua possibilità di comunicare si regge su fili sottili come ragnatele: basta cambiare il suono e l'ordine e il ritmo delle parole e la comunicazione fallisce. Quante volte, leggendo la prima stesura della traduzione d'un mio testo che il traduttore mi mostrava, mi prendeva un senso d'estraneità per quello che leggevo: era tutto qui quello che avevo scritto? Come avevo potuto essere così piatto e insipido? Poi andando a rileggere il mio testo in italiano e confrontandolo con la traduzione vedevo che era magari una traduzione fedelissima, ma neı mio testo una parola era usata con un'intenzione ironica appena accennata che la traduzione non raccoglieva, una subordinata nel mio testo era velocissima mentre nella traduzione prendeva un'importanza ingiustificata e una pesantezza sproporzionata; il significato d'un verbo nel mio testo era sfumato dalla costruzione sintattica della frase mentre nella traduzione suonava come un'affermazione perentoria: insomma la traduzione comunicava qualcosa completamente diverso da quello che avevo scritto io." (CALVINO, 1995, pp. 1.825-1.831). 
nuances, sombreados, cores), quando desfeita é impossível de se recuperar e refazer; mesmo guiados por uma "rota" pré-definida, os contornos não poderão nunca reconstituir o que havia antes; embora possam vir a estar próximos, orbitando o estado inicial, os pedaços não ocuparão os mesmos espaços. Em Páscoa de neve, Enrico Testa (2016, p. 57) traz, numa de suas prosas poéticas, esta imagem da impossibilidade de recomposição “"[...] de quem destrói um mosaico para recompor, depois, com as mesmas tesselas uma figura nova e - meu deus! - totalmente diferente”".

Não há dúvidas de que a tradução é um espaço de experiências comnas-pelas línguas. Eu diria até que é um momento privilegiado, pois é na "fisicidade" desse espaço que se dá a experiência singular e íntima, tanto com o texto quanto com a própria língua e a língua outra. O vocábulo experiência deriva do latim experiri, que significa provar, ação que pressupõe, por si só, um contato, um encontro, uma relação com algo queé, exatamente, provado e experimentado. Se observarmos, com mais atenção como faz Bondía (2002, p. 24), o radical de periri também se encontra em periculum, perigo, e o sufixo ex é o mesmo de exterior, existência, ainda presente em termos como estrangeiro (em espanhol extrangeiro e extraño). Portanto, a palavra experiência carrega consigo uma série de elementos que operam quando se dá um evento, um acontecimento, cuja partilha só é possível por meio de rastros que restam, às vezes, silenciosos. Em relação à tradução, as marcas dessa experiência - nem sempre tão legíveis e claras - podem ser percebidas no texto traduzido. Trata-se de uma vivência que se abre para a reflexão, pois "no ato de traduzir está presente um certo saber, um saber sui generis. [...] A tradução é sujeito e objeto de um saber próprio" (BERMAN, 2007, p. 18).

A língua de uma tradução, assim, não existe num a priori; ela só pode tomar corpo e se articular por meio das várias tensões, que por sua vez trazem as marcas da relação porosa entre as duas línguas e dos sujeitos que delas fazem parte. Trata-se, enfim, de uma língua - nas línguas - que se desenreda e se mostra a partir das tesselas ou dos cacos de um vaso, para retomar a epígrafe de Benjamin. O traço de "infidelidade" aponta para aquisições de marcas ausentes, como a imagem trazida pela prosa poética de Testa; um processo em nada intencional que aponta para sinais de afeição, fazendo do gesto tradutório um gesto crítico e envolvendo duas personalidades, duas línguas (incluindo seus recursos) e suas possíveis revelações e "descobertas" (TESTA, 2014a, p. 13). 
Outro ponto sensível tocado na citação de Calvino e presente na imagem da (des)composição do mosaico, é o da intraduzibilidade. Diz Calvino (apud MENEGHELLO, 2011, Anexo 2, p. 82): "Sabemos todos que a poesia em versos é intraduzível por definição; mas a verdadeira literatura, inclusive a em prosa, trabalha justamente sobre a margem intraduzível de cada língua. $O$ tradutor literário é aquele que põe em jogo a si próprio para traduzir o intraduzível"; eis aqui o momento do reconhecimento da alteridade e, com ele, a possibilidade de aberturas, de realização de uma língua na outra, como apontam Antoine Berman, Barbara Cassin, Henri Meschonnic. Deslocamentos e processos de agenciamentos fazem parte do jogo do traduzir, e é a partir dessas diferenças que a tradução se torna uma necessidade e um gesto ético. É portanto nesse espaço de porosidades e potencialidades que proponho a tradução de um poema de Enrico Testa contido em seu último livro, Cairn, publicado pela Einaudi, em março de 2018.

Poeta contemporâneo, professor catedrático de História da Língua Italiana e um dos mais interessantes críticos de poesia italiana, Testa tem seis coletâneas poéticas em circulação. Dentre elas, duas, Ablativo (TESTA, 2013, ed. it., e 2014a, trad. bras.) e Páscoa de neve (2008, ed. it., e 2016, trad. bras.), saíram pela Rafael Copetti Editor, em ocasiões em que o professor-crítico-poeta esteve no Brasil, numa parceria entre a Universidade Federal de Santa Catarina - UFSC e a Universidade de São Paulo - USP.7 Seu primeiro livro de poemas, Faticose attese (1988), tem apresentação de Giorgio Caproni, em um curto mas intenso texto indicando alguns traços marcantes de sua poética. Desse modo, desde seu primeiro livro, sua escrita teve acolhida positiva por parte da crítica, como foram confirmando outras resenhas ao longo dos anos: Giovanni Giudici, Alberto Asor-Rosa, Cesare Viviani (PETERLE, 2017).

A recente publicação Cairn (TESTA, 2018) é composta por nove seções, e o poema aqui escolhido para tradução está na quarta, intitulada "Album

7 Enrico Testa, em 2014, através do projeto n. 457634/2013-8 APV-CNPq, participou do lançamento de Ablativo na Casa Guilherme de Almeida; na USP deu uma conferência sobre Eugenio Montale e um curso intensivo no Programa de Pós-Graduação em Língua e Literatura Italiana dedicado à poesia, abordando Pier Paolini e Vittorio Sereni; na UFSC, participou do congresso Arquivos Poéticos: Desagregação e Potencialidades do Novecento Italiano e ofereceu uma disciplina intensiva também dedicada à poesia italiana a partir da década de 1960, focando Vittorio Sereni e Giorgio Caproni. As aulas na UFSC foram transcritas, revisadas e publicadas no volume Cinzas do século XX: três lições sobre poesia italiana (Rio de Janeiro, 7 Letras, 2016). 
di Capaneo" [Álbum de Capaneu]. Já aqui temos uma chave de leitura que perpassa pelos sete textos da seção, a do herói grego, pois Capaneu foi um dos sete reis que assediaram Tebas. Esse personagem da mitologia é caracterizado por sua desmedida soberba e presunção, que o levaram a desafiar Zeus, o qual, por sua vez, o fulmina com um raio. Capaneu morre, então, dizendo ferozes blasfêmias ao céu. Esse personagem foi retomado em algumas obras, como na Divina Comédia, em que Dante (1991), acompanhado por Virgílio, o encontra no Inferno (canto XIV, v. 43-72), num areal em brasa onde nenhuma planta cresce, local em que estão os blasfemadores. Capaneu, altivo e irado, tem um comportamento que chama a atenção de Dante, pois parece alheio ao que está ao seu redor, e ele mesmo fala de si aos dois viajantes. De fato, Virgílio, como guia, confirma sua arrogância e incapacidade de reconhecer a superioridade de outrem, sendo sua punição relacionada à raiva que sente.

É, portanto, essa imagem, a de um personagem soberbo, que Enrico Testa traz para pensar a atualidade em seus poemas. Um desdobramento que perpassa fantasmaticamente todas as composições dessa seção, trazendo um olhar atento e uma crítica pungente a aspectos da nossa própria contemporaneidade. Não se trata, como em outros poemas, de pequenas cenas ou flashes, o que está em jogo aqui é a amarga realidade - um apagamento do outro, um esquecimento do viver em comunidade lida com fina ironia.

Tendo em vista que o presente texto tem como objetivo refletir sobre aspectos da tradução poética, não poderia deixar de ser notado que o primeiro e o último poemas de Album di Capaneo são traduções propostas por Enrico Testa para os poemas “Bun's Outing” e “The way we live now", do poeta inglês Philip Larkin, os quais, em italiano, receberam os seguintes títulos: "Fuori per un paninho" [Fora para um sanduíche] e "Oggi si vive così" [Hoje vive-se assim]. ${ }^{8}$ Com isso, ele repete pela terceira vez um gesto iniciado em 2008, com Páscoa de neve, a saber, a inclusão de versos de Larkin em suas coletâneas.

Continuar a pensar o modo como o poeta italiano se apropria dos versos do poeta inglês, fazendo-os seus, seria algo muito interessante,

8 Interessante perceber que Testa não traduz os poemas por inteiro, escolhe somente as primeiras estrofes de cada um. Além disso, introduz aspas inexistentes nos textos em inglês de P. Larkin, ressaltando assim, talvez, o gesto de "apropriação" que se realiza nessas traduções. As aspas, de fato, podem ser lidas como um indício dessa fala do outro, que a posição do poema no livro do poeta italiano pode despistar. 
mas não é esse o escopo nesta sede. ${ }^{9}$ Todavia, é interessante atentar para o fato de que o gesto tradutório, de uma maneira ou de outra, está presente nessa escrita, tanto por meio de uma esfera mais íntima, na qual confluem as viagens realizadas e os deslocamentos por elas produzidos, as experiências com as línguas e a percepção de outras formas de apreensão do que há ao redor, quanto por meio de uma esfera mais crítica e talvez formal que, não desconsiderando a primeira, envolve o pesquisadorpoeta-pesquisador que organizou o volume Quaderno di traduzioni de Giorgio Caproni (1998) e, mais recentemente, o de Eugenio Montale (2018), e traduziu High Windows [Finestre alte] de Philip Larkin, em 2002, para a Einaudi.

No prefácio à edição italiana de High Windows, alguns pontos identificados na poética de Larkin podem servir para pensar a própria escrita de Testa, pois, ao mesmo tempo em que lê e fala do outro, também não deixa de tratar de si mesmo. Vejamos dois exemplos. O primeiro deles é quando Testa evidencia a importância da encenação do caráter comum da existência, o qual se abre em uma série de imagens desdobráveis que fazem da poesia de Larkin uma "realidade quase errática, em lento, mas sensível movimento em ribanceiras e penhascos da complexidade" (LARKIN, 2002, p. VIII, tradução minha). O segundo refere-se ao plano da composição do livro como um todo, em que poemas com traços narrativos se alternam com outros mais elípticos. A disposição identificada no laboratório de Larkin para certa ironia, para a variação de registros no trabalho com a língua, enfim o olhar meio enviesado em relação às coisas parece também estar presente na escrita de Testa. Nessa trama, que vai sendo tecida com Larkin dentro e fora de seus textos poéticos, é possível notar como esse espaço do "entre" sofre pequenas e significativas alterações. Se em Páscoa de neve e Ablativo a voz incorporada de Larkin aparece em seções separadas das da voz do poeta italiano, mesmo com a existência de uma clara relação de hospitalidade, em Cairn, essa divisão espacial, essa espécie de limiar, é suspensa.

9 A pesquisa de mestrado de Luiza Kavinsk Faccio (bolsista CNPq), "Interseções entre Enrico Testa e Philip Larkin", ainda em desenvolvimento, no PPGLIT/UFSC, segue essa direção.

10 "[...] una realtà quasi erratica, in lento ma sensibile movimento sui pendii e sulle rupi della complessità”. 


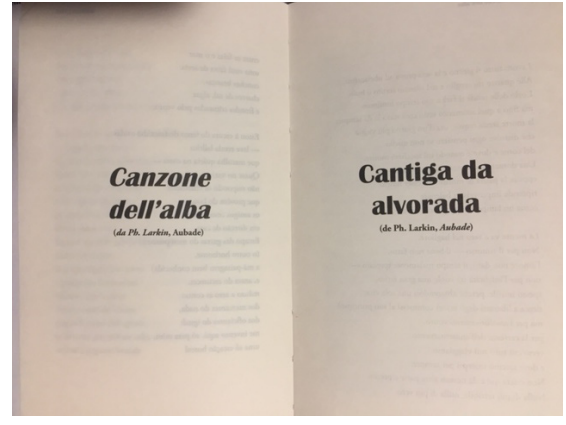

Figura 1. Reprodução de Páscoa de neve (TESTA, 2018, pp. 104-105).

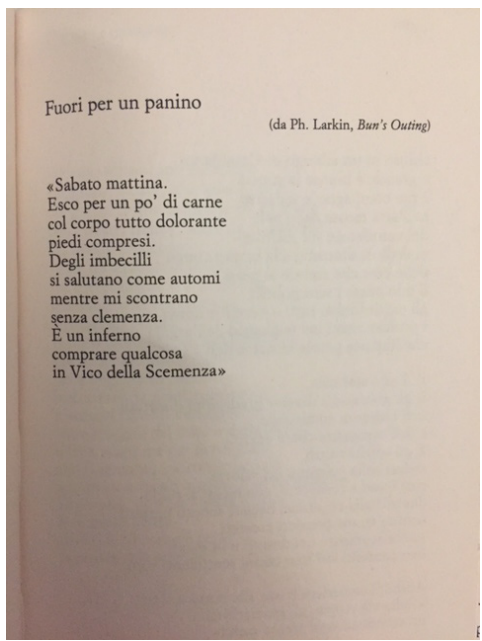

Figura 3. Reprodução de Cairn (TESTA, 2018, p. 45).

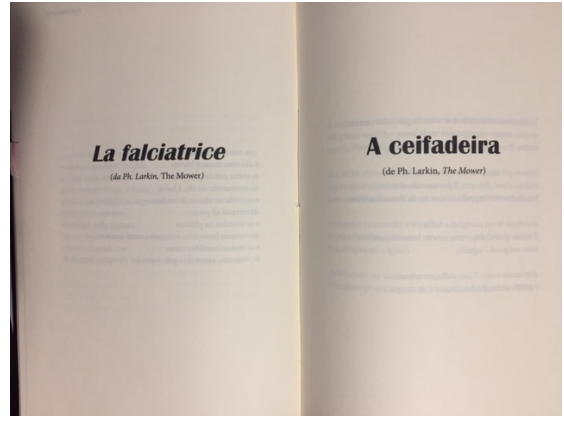

Figura 2. Reprodução de Ablativo (TESTA, 2018, pp. 138-139).

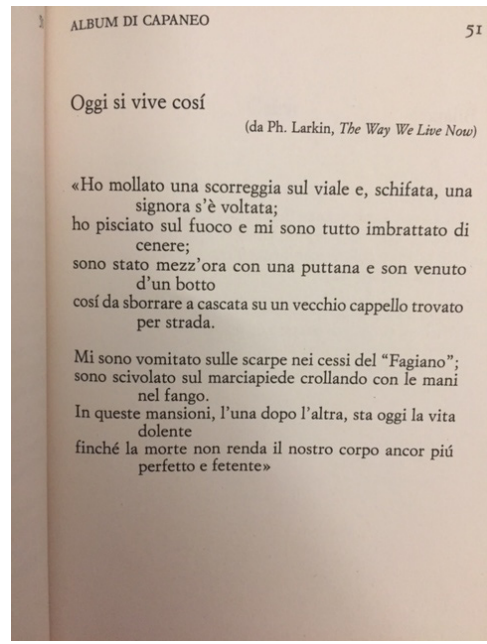

Figura 4. Reprodução de Cairn (TESTA, 2018, p. 51).

As quatro reproduções das apresentações dos poemas de Larkin nos livros de Testa mostram como esseestar-entre-línguasvai se intensificando, indo em direção a práticas de aberturas, sempre mais intensas, até que se dá, efetivamente, a entrada do outro na própria morada. Tal entrada é explicitada em Cairn, quando já não há uma separação entre as vozes, sendo o poema de Larkin antropofagicamente trabalhado. Um forte sinal de que essa morada necessita desse e dos outros estranhos que ali convivem por meio de seus rastros, conforme se lê na nota final do livro de poemas, o qual traz nomes que de algum modo pervivem nas páginas de 
Cairn: Lucrécio, Tanizaki Jun’ichirō, Patrick Leigh Fermor, Peter Handke, W. Sebald, Ovidio, H. Pinter."

Em "Album di Capaneo", os sete textos trazem esse olhar oblíquo, a captar as imagens de um "eu" que, caminhando pela rua, esbarra com dois imbecis autômatos ["Bun's Outing”]; de um quarto de hotel em Casablanca, que propicia o distanciamento necessário para pensar o próprio país e seus personagens políticos; de rodas endógenas e auráticas de poetas que criam seus mitos e modismos; do caráter impiedoso da história de uma Roma babélica, ao qual é aproximada a rima-blasfema mal-Natal; de uma abstenção, quando o "eu" se coloca à parte, em minoria em relação inclusive a si mesmo; e, enfim, de um "eu" que descreve algumas ações realizadas, as quais mostram como o mundo está de cabeça para baixo e somente a morte pode deixar esse corpo mais perfeito e fedido ("The way we live now").

Dando continuidade a essa aproximação, o primeiro poema da seção é "Fuori per un paninho", que é a revisitação de "Bun's Outing”. O segundo poema, sem título, que começa com "chiuso in un albergo di Casablanca" [fechado num hotel em Casablanca], do ponto de vista da tradução há um aspecto importante a ser observado no verso 9: "gli escalofonisti tutti vecchi e nuovi -". Como traduzir escalofonisti? A discussão colocada por Benjamin e Caproni em relação à palavra "pão", poderia ser agora retomada. O termo escalofonisti é um neologismo usado pela primeira vez em 3 de setembro de 2015 pelo Papa Francesco. Mas, como se chega a ele? Em abril de 2013, o Papa traz à baila num discurso o dano que homens e mulheres da igreja que são "carreiristas" e "alpinistas" podem causar ao usarem o povo como trampolim para a ambição pessoal. Até aqui tudo bem. Porém, ao longo do tempo, quando retoma essa questão, o Papa usa outros termos de mesmo campo semântico. Em maio de 2013, usa "carrieristi e nepotisti", em junho de 2014, "cristiani vantaggisti", depois em maio de 2014 retoma os mesmos termos para em setembro de 2015 finalmente usar "escalofonisti". É esse, portanto, o contexto em que a palavra é gerada. Não há nenhuma dificuldade de apreensão e compreensão, os termos usados antes de 2014 são correspondentes, são sinônimos. Trata-se de um adjetivo, cujos traços semânticos "visado" e "objeto" estão claros, como no caso do "pão", disso não há dúvidas. Porém, o que está em jogo são exatamente os harmônicos

$11 \mathrm{O}$ mesmo procedimento pode ser encontrado em outros livros do poeta, ao indicar nas notas finais, alguns dos companheiros de leitura que são trazidos, sob diferentes formas, em seus versos. 
produzidos por esse termo, quando lido/escutado por um ouvido italiano, cujo repertório possui acordes capazes de captá-los.

Esse fenômeno foi matéria no suplemento "Letteratura" do jornal Corriere della Sera, em 13 de setembro de 2015, através da resenha do livro Maria Ines, hai visto che non ho messo le scarpe rosse?, de Luigi Accattoli. A escuta, aqui, logo tem um efeito que faz vibrar. Mas, de onde terá vindo ao Papa a ideia de escalofonisti? É uma derivação de escala [escada], ou seja, scalatori, que em português corresponderia a "escaladores", termo que continua fazendo parte do mesmo campo semântico acima e poderia ser usado no sentido dado pelo Papa, numa tradução. Segundo Luigi Accattoli, esse é mais um exemplo do itañolo do Papa, que vive numa relação entre línguas.

Agora, como seria uma possível tradução de: "gli escalofonisti tutti - vecchi e nuovi -"? O embate com a tradução desse verso, por si só, evocaria esse rápido "panorama" (sempre incompleto) e a atmosfera de toda uma sociedade, que é a italiana. Desconsiderar essas camadas do termo e tratá-lo da mesma forma que as outras palavras presentes no verso significa anular toda a questão política e social que ele evoca consigo, mais do que isso, significa não considerar o outro e eliminar suas idiossincrasias. A questão da intraduzibilidade, posta aqui, emerge com toda sua intensidade porque não está em jogo o que não se traduz, mas "o que não cessa de (não) traduzir”, expressão de Barbara Cassin, retomada por Simone Christina Petry (2017) e Claudio Oliveira (2016), em textos que pensam o trabalho da filósofa francesa frente ao Vocabulaire européen des philosophies - dictionnaire des intraduisibles. Os movimentos colocados em ação, aqui, apontam para o embate com o outro e perpassam por camadas interligadas do linguístico, do político e do social. Nesse sentido, não se trata de perda, mas sim de "ganho" - o maior tornado possível, justamente, pelo gesto da tradução - que se realiza no desvio, uma terceira via, uma escolha ética pela abertura, pela hospitalidade, ao dar a ver a relação entre as línguas e culturas e suas singularidades (sem apaziguá-las). Um gesto que está, sobretudo, para o reconhecimento de alteridades e para a manutenção da abertura aos e com os outros. Talvez seja inútil lembrar nesse caso, mais uma vez a atuação de Testa como professor de História da Língua, atuação esta que não fica em segundo plano na escolha do neologismo, que evoca uma série de situações do seu vivido.

É, portanto, a partir dessas considerações iniciais que se propõe a tradução do terceiro poema da seção "Album di Capaneo". 
vivemos sem entender nada disso

fingindo, alguns, de entender tudo

dias a fio passados no ócio

dos nossos hobby horse sem valor:

brigas manias crenças

rodas de pavãozinhos sediciosos

ritos de elevação ou de abjeção

esconjuros vozes impositivas

ultrajes à humildade.

De pouco valem teólogos de festivais

que sabem ainda menos

que as beguinas das aldeias

maltratadas por poetas arrogantes

e augustos filósofos verbigerantes

sob o signo do mito ou da moda;

e cães maculados de dentes amarelos

que rosnam, em seu provento,

espírito de serviço e senso de pertença.

Pode-se, para todos - tenham certeza! -

também pedir dispensa.

Afinal, a conta é zero:

nossa única ciência.

viviamo senza capirne niente

fingendo, alcuni, di capirne tutto

dei giorni in fila trascorsi nel trastullo

con i nostri hobby horse da strapazzo:

liti manie credenze

ruote da pavoncelli sediziosi

riti d'elevazione o d'abiezione

scongiuri voci impositive

oltraggi all'umiltà.

A poco servono teologi da festival

10

che ne sanno ancor meno

delle beghine da paese

bistrattate da poeti tracotanti;

e augusti filosofi verbigeranti

sotto il segno del mito o della moda;

e iene maculate dai denti gialli

che ringhiano, a loro tornaconto, 
spirito di servizio e senso d'appartenenza.

Se ne può, di tutti - state certi -

fare anche senza.

Alla fine, il conto è zero:

la nostra sola scienza

(TESTA, 2018, p. 47)

Se no poema anterior o alvo eram os políticos e os carreiristas, agora, o espaço é outro, talvez um pouco mais reservado; contudo a marca de Capaneu persevera. O primeiro verso, "vivemos sem entender nada disso", é uma declaração que se contrapõe às demais que se desdobram a partir do segundo: "fingindo, alguns, de entender tudo". Parece aqui haver um movimento circular e contraditório, um embate ("sem entender" e "entender tudo"): na verdade, mais do que um embate, há aqui um traço significativo dessa escrita que parece se originar de um espírito autocontraditório, que é também uma de suas potências. De fato, para Testa (2014b, p. 6), como afirma em uma de suas entrevistas, "a poesia é [...] uma figura da aporia. E para 'tolerar' a aporia, a atenção e a paciência são necessárias".

Essas observações primeiras não estão distantes das questões colocadas para se pensar a tradução, que também pode ser lida por esse viés da aporia. A poesia para Testa é concebida como uma busca por uma convergência no plano linguístico e sentimental com o leitor, como ele mesmo declarou em entrevista publicada na revista Manuscrítica em 2014:

[...] penso a poesia como busca por um ponto de convergência, linguístico e "sentimental", com o leitor. O que não significa minimalismo negligente, italiano pobre ou submissão aos mitos da sociedade de comunicação, mas significa, sobretudo, que o "partilhar a vida" esteja na origem da escritura e da tensão no contato com o outro. Colocar-se "entre" a língua de todos e numa invenção verbal nunca exibida traz consequências linguísticas inevitáveis. De um lado, no plano imaginativo e teórico, a convicção de que quem escreve, melhor dizendo, o eu textual, e quem lê não respondem a um identikit preciso, a uma nítida individualização; de outro, o fato de ambos se colocarem no espaço que se distende entre ninguém e qualquer um. Só nesse interstício há esperança de dar voz a alguém e de encontrar no murmúrio ou no silêncio, alguém que escute. (TESTA, 2014b, p. 40)

Ao fazer essas colocações, o poeta sublinha o traço, do "com-", da partilha presente na poesia, mas que só é possível por meio de um contato e da tensão com o outro. Nesse sentido, sua poética se distancia tanto das 
práticas de vanguarda quanto das de uma voz "absoluta”. Ele escava na língua um "entre”, à procura desses “interstícios”.

O olhar enviesado toca, agora, o comportamento de poetas/filósofos que fingem entender tudo e parecem estar acima de tudo e de todos, porém, no fim, tudo não passa de encenações. Não há nesse poema recurso a neologismos ou termos mais específicos; o vocabulário é simples (o que não significa automaticamente fácil), mas calibrado com alguns termos que fogem de uma linguagem do uso comum. $\mathrm{O}$ adjetivo ao final do v. 13, "tracotanti", na tradução "arrogantes", evoca a figura de Capaneu; é interessante lembrar que o substantivo tracotanza é usado no Inferno (canto VIII, v. 127). A passagem na tradução de "tracotanti" para "arrogantes" traz em si um pequeno desvio necessário, que deixa intraduzível o movimento de "transbordamento" presente na semântica do termo em italiano.

Há aqui, para lembrar a discussão de Barbara Cassin, em Éloge de la traduction (2016), um sintoma semântico que vem à tona, justamente, no gesto tradutório que, ao colocar em relação, nesse caso específico, o par italiano-português, expõe suas especificidades e singularidades, ao mesmo tempo que abre para reflexões. É nesse sentido que leva ao pensamento, à crítica, e que a intraduzibilidade deve ser concebida e vivida, como uma tensão entre as línguas, que retorna para as próprias línguas ressaltando seus usos.

Com isso, percebe-se que a intraduzibilidade não é um obstáculo, uma barreira para o tradutor, mas é, sem dúvida, um valor, que leva a reflexões sobre o processo, sobre as línguas e expõe as relações, os contatos e contágios. A existência dos intercâmbios e da comunicação não se dá sem traições (BERMAN, 2007, p. 41), que nessa operação deixam de ser vistas com a carga negativa da "perda". De fato, é nesse espaço com o outro que a força ética e a política emergem. Nessa linha, a tradução se dá a ver através desse relacionar-se com o fora, sem querer sua simplificação ou transformá-lo em algo semelhante. Exatamente por posições como essas, o gesto tradutório pode ser um paradigma contemporâneo, não só no campo dos saberes, mas, sobretudo, no do modo de estar e fazer parte do mundo.

Todo o poema aqui traduzido se desenvolve numa única estrofe formada por 22 versos -, que parece se dar num fluxo de pensamentoa partir de uma situação evocada por um olhar bem crítico. Dentro dessa estrofe podemos pensar em quatro momentos: 1) a apresentação geral da situação, 
que termina com os dois-pontos, ao final do v. 4; 2) o desdobramento dela, nos versos seguintes, com algumas descrições e caracterizações, mesmo não se sabendo ainda quem participa dessas tertúlias de pavãozinhos esse segundo momento termina com o primeiro ponto final no v. 9; 3) depois da apresentação do cenário, é possível começar a explicitar quem são os "pavãozinhos sediciosos", que no v. 10 recebem outra nomeação: "teólogos de festivais”. O tom de irritação com o comportamento desse grupo cresce no momento em que são identificados (poetas e filósofos). O nível de indignação é alto e, ao invés da coroa de louros ou da imagem da coruja (símbolo da sabedoria), lhes é atribuída a imagem da iena - na tradução cães (retornaremos a isso mais adiante) - com dentes amarelos; 4) o último momento, enfim, como acontece muitas vezes nos poemas de Testa, é uma reflexão sobre o quadro que foi sendo construído: não há dúvida de que esse tipo de comportamento não serve para nada, então, é possível - e até benéfico - se "livrar" dos "pavãozinhos sediciosos". Depois dessa dispensa sem volta, num único gesto, há uma suspensão que (re) abre o poema, inclusive porque, com a ausência do ponto final, a reflexão parece continuar sorrateira no restante do espaço em branco da página.

Se por um lado é possível fazer essa divisão interna, por outro todo o texto é um contínuo. Basta pensar na sensação de entrar no meio de algo, sensação esta sugerida desde o primeiro verso, com a opção pela letra minúscula de "vivemos". A impressão deixada é a de que o início está em outro lugar, sendo o leitor catapultado no meio da situação de discurso pelo uso da primeira pessoa do plural (vivemos). Esse traço é característico dos poemas de Testa, que quase nunca apresentam título, quase sempre se iniciam por letra minúscula e, enfim, normalmente, terminam (não acabando) sem um ponto final. ${ }^{12}$ Só um único poema em "Album di Capaneo", além das releituras de Larkin, possui título:

12 Outros críticos já trataram desse aspecto que se tornou um traço de sua escrita. E, em relação a isso, lembra-se aqui o poema de "Páscoa de neve" (TESTA, 2016, p. 3): "podes começar mesmo/ sem um início/ ou, como os indianos, deambular apagando/a cada passo o princípio;/ e terminar sem fechar/ interrompendo desarmado a palavra/ como se já não a dissesses tu"'; que, colocado em abertura, assume nuances que vão do equilíbrio do poema para a própria estrutura do livro em si. Outro dado interessante é que esse movimento retorna agora, em 2018, no último poema de Cairn, que se inicia com uma negação para chegar à afirmação: "Non possiamo ricominciare ancora./ Soltanto possiamo ancora finire.' 'Ma non abbiamo mai finito.'/ 'Oh sì, non crederlo. / Abbiamo finito molte e molte volte./ non una sola volta./ e ora possiamo finire di nuovo. E ancora e ancora./ Senza un inizio"” (TESTA, 2018, p. 116). 
"Bilancio" [Balanço], outro termo, ou melhor, indício que poderia perfilar todo este conjunto de versos.

Metricamente, considerando o texto em italiano, tem-se um leque de medidas variadas, do tradicional hendecassílabo ao novenário, à redondilha maior e a outras variações. As rimas mais evidentes são capirne e capirne (r. interna e anáfora, v. 1-2), elevazione e abiezione (r. Interna, v. 7, que podem criar uma assonância com sediziosi), tracotanti e verbigeranti (v. 13-14), appartenenza, senza, scienza (v. 18, 20, 22), que foram mantidas na tradução, por meio de algumas modificações. Há uma trama de sons. O som talvez mais ameno e pacato dos primeiros versos aos poucos é substituído por um som mais duro, anunciado no final do verso 3: trascorsi, trastullo, que vai se reproduzindo com modificações e alternâncias nos demais, até que, a partir do v. 18, é suspenso para dar lugar ao jogo da rima final em scienza.

Os dois primeiros versos possuem um ritmo embalado pelo

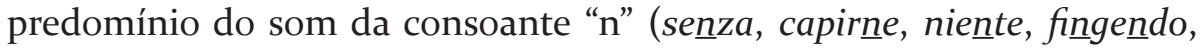
alcuñi, capirne). Ao ler em voz alta, a sensação que se pode ter é a de que o final do segundo verso volta ao primeiro, algo parecido com um movimento circular (ver nota 9), que logo abaixo é interrompido por um som mais duro, que perpassará por todo o poema. Se o poético exige outra ordem, outro regime de sentido, inclusive outro ritmo de aparecimento, nesse poema, o verso inicial, para além do ritmo, já coloca uma questão para a tradução em português de algo que se repete depois mais três vezes (v. 2, 11, 19), a saber, a partícula ne, que é um complemento do verbo capire. O uso dessa partícula no primeiro verso traz um desvio em relação à língua e marca um traço de oralidade. Há aqui um esgarçamento, um outro uso, poder-se-ia até dizer uma profanação. De fato, normalmente, a partícula ne é trazida para o discurso quando o seu referente já foi mencionado em algum enunciado e é conhecido por aqueles que estão envolvidos. Em "viviamo senza capirne niente", ela pode se referir à situação evocada pelo verbo viviamo, mas, mesmo assim, há um fora que será melhor explicitado no decorrer do poema.

Tal posição, se por um lado reafirma a ideia de o leitor ser projetado para um discurso que está em andamento, por outro impede-lhe a partilha do contexto situacional - neste momento. Isso acontece porque a partícula ne está apontando também para algo que está fora do poema e que será trazido nos versos seguintes. Tal posição (o primeiro verso) desloca e profana uma construção mais tradicional, pois os indicadores 
da dêixis "têm em comum o traço de se definirem somente em relação à instância de discurso na qual são produzidos, isto é, sob a dependência do eu que aí se enuncia”, conforme coloca Benveniste (1976, p. 288). A "instância do discurso", com efeito, está fora, mas é imediatamente trazida (sem seu referencial, há aqui um esburacamento) pelo uso e pela posição escolhida, que só recebe maiores detalhes à medida que o próprio poema se desdobra. É como se esses versos iniciais ecoassem a imagem benjaminiana do leque: "a faculdade da fantasia é o dom de interpolar no infinitamente pequeno, descobrir para cada intensidade, como extensiva, sua nova plenitude comprimida, em suma tomar cada imagem como se fosse a do leque fechado, que só no desdobramento toma fôlego [...]" (BENJAMIN, 1987, p. 41).

Em várias ocasiões, nas traduções da língua italiana, a partícula ne deixa de ser traduzida, sendo eliminada por, aparentemente, não comportar nenhum dano ao texto. Contudo, pular na tradução essa partícula tão usual na língua italiana significa apagar um traço do rastro desse idioma, uma peculiaridade diante do português. Na proposta de tradução do poema, optou-se pelo acolhimento das especificidades e pela exposição das alteridades, ou seja, pela relação entre as línguas. Se o primeiro verso foi o espaço da acolhida do outro, o segundo é aquele da exposição da língua que recebe. De fato, há no poema em italiano um paralelismo intraduzível, mas foi, exatamente, essa tensão que proporcionou expor a relação e a convivência das duas línguas envolvidas.

viviamo senza capirne niente

fingendo, alcuni, di capirne tutto

vivemos sem entender nada disso

fingindo, alguns, de entender tudo

Uma omissão da partícula "ne", no primeiro verso do poema reproduzido acima, faria com que : 1) a situação se generalize; 2) se perca desde o início a especificidade para a qual Testa está chamando a atenção. ${ }^{13}$ O que faz com que a escolha do uso de "disso", que seria dispensável num outro viés tradutório, seja imprescindível por ser sintomática. A presença de "disso" acolhe a "suspensão" provocada no leitor do texto em italiano,

13 Lembra-se que a importância dos dêiticos para a poesia italiana contemporânea foi um dos tópicos abordados por Enrico Testa (2015, pp. 22-41) em "A entrada do terceiro. Pessoa. Língua, poesia”. 
e gera um estranhamento que obriga a um prolongamento, já que o verso poderia ter terminado em "nada”.

Um comportamento semelhante da partícula "ne" tem-se no verso 11: "che ne sanno ancor meno", "que sabem ainda menos". Porém, aqui, não há a mesma necessidade de se traduzi-la, uma vez que a função é um complemento do verbo saber, que chega implícito no discurso, pois já foram fornecidas algumas referências essenciais para o enquadramento da situação. Note-se que a partícula ne age, nesse momento, não mais em relação a um fora, mas sim a algo que foi trazido para o interior do poema e para este verso em específico. Na língua italiana, essa repetição é essencial para o funcionamento sintático e orgânico do verso, traço que não tem o mesmo comportamento em português e, portanto, permanece na esfera do intraduzível, de uma ausência que é necessária. O terceiro e último caso da presença da partícula ne encontra-se mais para o final do poema, v. 19, cujo sentido só é finalizado no verso seguinte:

Se ne può, di tutti - state certi -

fare anche senza.

Pode-se, para todos - tenham certeza! também pedir dispensa.

Agora, o contexto situacional já está claro e é compartilhado, porque foi sendo colocado ao longo dos demais versos. A partícula "ne" é uma deslocação e antecipa "di tutti”, que recupera as expressões "pavãozinhos sediciosos" e "teólogos de festivais". Tal construção e o tom desses dois versos apontam para o posicionamento de não partilha entre "eu" e os comportamentos narcísicos e autorreferenciais. Aqui, a partícula aponta não para fora do poema ou do verso, mas para a segunda parte do enjambement, que se inicia com a pausa, assinalada pela vírgula. Essa antecipação do termo "di tutti" é um traço da língua italiana falada, da oralidade, que Testa acolhe em seu laboratório poético. De fato, ele abre o espaço do poético para a pluralidade da língua italiana, para suas variedades e diferenças de uso - uma língua em movimento -; em alguns casos há até a inserção de termos em língua estrangeira. Como dar conta desses aspectos numa tradução? São particularidades tão peculiares que arriscar uma tradução significaria diminuir sua força e apagá-las. Trata-se aqui mais uma vez da esfera do intraduzível, que mostra toda sua potencialidade, na exposição da relação e, por conseguinte, na de seus embates. 
Entretanto, diante das colocações feitas até aqui, não faz sentido falar de impossibilidade da tradução, mas sim de "elogio" da tradução, retomando o título do livro de Barbara Cassin e o último capítulo, porque o intraduzível se configura como a dimensão mais fundamental de uma língua, a mais íntima. E somente através do gesto tradutório, que é uma exposição, um espaço de contatos, contágios e conflitos, é que se pode chegar a essa dimensão, ou seja, à relação com a alteridade, cuja existência indica que as singularidades existem e permanecem. As singularidades exigem uma ética, sendo abolidas e apagadas através da violência de uma visão hegemônica, de uma imposição.

A intraduzibilidade poderia também ser lida como a possibilidade em negativo, uma energia que necessariamente não é figurativa ou apreensível. Diz Christian Prigent (2017, p. 34), "Poesia = alcance de uma onda negativa no entre-dois entre sentido e som. Indicação e interdição simultâneas de uma possibilidade de ligação do sentido e do som”. Se o início do texto poético de Testa apresenta uma tendência à prosa, para retomar Prigent, há simultaneamente uma "atonia da prosa" por meio dos cortes, das cesuras, dos intervalos que também constituem o corpo do poema, que, para além do poeta e do leitor, passa a ter uma voz própria. É nesse exato momento que a poesia se faz língua, que a realiza.

Depois do som, talvez envolvente, dos primeiros dois versos e da constituição de um corpo próprio, é possível perceber como tal som é capaz de significações. Há, no acontecer do poema, uma predominância de sons dentais, bilabiais e alveolares. A consoante " $r$ " sonora é uma vibrante que está presente em 12 dos 22 versos no texto em italiano, principalmente entre os v. 3 e 14, quando se desdobra toda a tensão do poema. Tomemos como exemplo o verso 13, que é central para a caracterização final desses poetas narcísicos ali citados: "bistrattate da poeti tracotanti". Há neste verso todo um movimento sonoro, regido pelas consoantes " $t$ " e "r", que está em sintonia com a dureza e o desprezo dos poetas em relação às beguinas e ao caráter arrogante, já mencionado anteriormente. $\mathrm{Na}$ tradução proposta, com "maltratadas por poetas arrogantes" manteve-se um equilíbrio, já que é muito presente o som da consoante " $t$ ", apesar de ter-se desviado da consoante "r", porque com "arrogantes" inseriu-se um som velar; mas a cadência - a pulsação - do verso foi mantida.

Em termos textuais, é interessante observar a ausência de pontuação interna, que foi mantida, inclusive no trio de substantivos privados também de conjunção, "brigas manias crenças", o que dá pistas do 
comportamento dos "pavãozinhos sediciosos", que ao longo do poema vão ganhando outras nomeações (vs. 6, 10, 13, 14, 16). O termo "poetas" aparece no v. 13 e é elevado ironicamente no v. 16 a "augustos filósofos", imagem que é descontruída pelo adjetivo "verbigerantes". Tanto o v. 14 quanto o v. 16 iniciam-se com a conjunção aditiva "e" em função anafórica, e o que vem depois dessa ligação são duas imagens que parecem opostas: "augustos filósofos" e "cães maculados".

Outros contornos passam a permear, assim, essa imagem no v. 16, carregada de sarcasmo. A glória, o respeito e a imponência, contidos no adjetivo "augusto", mesmo que usado de forma irônica, são esgarçados até figurarem, no seu reverso, nos dentes amarelos dos cães. Em termos de tradução, é preciso voltar para a cultura italiana e pensar em alguns animais que são usados com frequência para caracterizar atitudes humanas. O primeiro deles é o leone [leão], cuja característica é a coragem, bravura, que, nos humanos, é considerada uma virtude. $\mathrm{O}$ segundo é a lince [lince], outro mamífero carnívoro, que consegue captar o que acontece no entorno rapidamente; diz-se "occhio di lince", em italiano, para uma pessoa perspicaz e inteligente, que consegue intuir as coisas de longe. O terceiro é a volpe [raposa], que, como no Brasil, é caracterizada pela astúcia e esperteza. O quarto, que mais nos interessa, para entender melhor a simbologia trazida para o poema, é a iena [hiena], mais um felino carnívoro que, em sentido figurado, evoca uma pessoa cruel, feroz, agressiva. Para manter o paralelismo da imagem de pessoa má, perversa, uma primeira opção foi "fera”, que poderia indicar qualquer um desses animais e acentuaria o lado animalesco e feroz, mas não seria necessariamente o mais adequado, porque em italiano o termo usado é bastante coloquial e comum. Além disso, fera não é um animal específico, como nos demais casos. Quando dizemos em português "ele virou uma fera", acentuamos muito mais o caráter raivoso do que o perverso. Além disso é preciso manter a atenção nos "dentes amarelos" e no verbo "rosnam".

A escolha final foi pelo termo cão, que é bem diferente de cachorro apesar de o "visado", para retomar Benjamin, e o "objeto", com Caproni, serem os mesmos. O desvio colocado abre para a cadência do verso, pois a nasalização de cães volta em dentes, e o plural masculino de maculados retorna em amarelos. Opções que trazem para o primeiro plano a relação entre as línguas envolvidas, que resistem a uma universalização e ao predomínio de uma visão hegemônica. Não se trata de um caráter 
substancial que deva ser mantido, mas, sobretudo, do caráter relacional, que é posto em evidência através do reconhecimento e da relação, ficando em devir com o intraduzível. Teria sido possível indicar o termo "hiena", mas o que se perderia com ele? Não se anularia, nesse caso, a peculiaridade do português? As diferentes línguas produzem a diferença entre os mundos, e essa pluralidade aponta para uma performance discursiva.

Um verdadeiro sistema de tensões, agindo em vários níveis (lexical, rítmico...), dá forma ao corpo do texto e à sua voz. Assim, é desnudando e esburacando que o poema escava e se instaura numa suspensão, numa passagem que permanece em aberto; e o som inicial da consoante "n" retorna, agora, no final. Há, sim, nesses versos a tentativa de construir sentidos que não se encerram em si mesmos. Do mesmo modo que o poema começa, como se o leitor fosse colocado no meio de um discurso em curso, que segue seu ritmo próprio, marcado pela letra inicial minúscula do texto (vivemos), o poema termina com a palavra "ciência", que chega reverberando em "pertença”, "licença”, sem contudo terminar definitivamente. Para a manutenção dessa rima final (appartenenza, senza, scienza), foi preciso fazer um pequeno desvio, optando-se pela expressão "pedir licença".

Pede-se, agora, licença àqueles que seguem, talvez seguros de si e com ar de vidro, para abrirmos ao percurso tortuoso e indecidível da letra, onde ressoa o ser-nas-línguas. Não identificação, mas ponto de confluência que faz pensar, que aproxima experiências sem igualar, que escava através delas um espaço do "entre". A linguagem, assim, não é vista como um canal, mas como uma força dada pela pluralidade das línguas. Um abrigo que só pode ser "precário", por isso, retomando um verso de Testa (2016, p. 27): “a decepção da origem”. A linguagem, assim, não é vista como um canal, mas como uma força dada pela pluralidade das línguas. As palavras não são apenas símbolos de coisas, elas possuem cores, tonalidades, densidades, movimentos. $\mathrm{O}$ ato de traduzir se torna, assim, um exercício crítico diante das escolhas que envolvem diferentes planos - sintático, semântico, fonético, morfológico -, os quais são trabalhados na tensão entre aproximação e distanciamento do texto de partida, de uma origem que permanece, resta aporeticamente sempre lá, mediante seu embaçamento. A transfiguração do original em outra letra, portanto, coloca em primeiro plano o infinito processo conflituoso de leitura de um texto. Um dos primeiros elementos a serem desestabilizados é a língua, pela própria experiência da violência do estrangeiro; se antes ela poderia 
ser espaço de certo domínio, agora ela é um espaço mais do que precário, uma vez que é colocada em jogo e tensionada até seu limite. Nesse sentido, a língua (ou melhor, seu pressuposto domínio) é um abrigo "temporário", cuja potência é dada justamente por sua "precariedade". Uma imagem poética relativa a essa impossibilidade de "manutenção" da origem é dada num poema de Páscoa de neve. O eu nesses versos tenta perfazer o mesmo caminho de quando era garoto nos Apeninos, com o objetivo de encontrar e rever, no verão, as fontes das torrentes. Tal tentativa e desejo colocados no ato de rever a mesma imagem gravada na memória só pode resultar numa expectativa impossível de se concretizar. A experiência, agora, é outra: violenta a primeira e quebrada a "promessa" que não se realizou. De fato, ao chegar nas fontes, a sensação é a da "decepção da origem" (2016, p. 27). Dessa forma, a tradução segue na direção do pensar e compreender como as diversas línguas geram formas diferentes de comunicação, sendo o comum e a convivência um objetivo a ser alcançado.

Talvez o processo de tradução desse poema já estivesse presente em mim desde a primeira vez em que o li, e ainda continue por vias silenciosas, experiências singulares da letra. Os versos em português impressos nestas páginas são os que, como coloca Caproni (2017, p. 239), testemunham a "experiência em ato (uma experiência mutuada entre poeta e leitor), e não referida”, uma experiência da relação entre línguas que, sabe-se, não é fixa. De fato, quando falamos e escrevemos, não podemos deixar de pensar, de manter em uma espécie de suspensão as palavras. Por isso, como lembra Agamben (1982, p. 10), o importante no bosque da língua (cheio de sons, harmônicos e vibrações) não é a trilha da palavra que estamos percorrendo, mas sim o zunido, o chirrio, o sibilo, o gemido, o chiado, o zizio, impossíveis de serem tocados. Uma potência latente encontra-se não no ato de apreensão, mas na percepção - que num átimo escapa - desses rastros fugazes. Essa potência é pensamento, e a ética está em como falamos.

\section{AN EXPERIENCE BETWEEN LANGUAGES: TRANSLATING ENRICO TESTA}

Abstract: To think of translation as perpassing and experiencing by two (or more) languages means plunging into the vortex that this act itself produces. To translate, as theoreticians, poets and writers had already talked, just to remember Italo Calvino, is the best way to read a text, because the translator does not have the common reader's alibi, which skips the more elliptical parts without major concerns. Reflecting on a text, through this confluence, means choosing instruments and potentialities to enter, penetrate and 
make alive the body and the voice of the poem - even with some deviations. Understanding the act of translation as an event, an experience which is in-of-through the language, an experience of thought and ethics, we propose a discussion of this gesture from a recent poem by Enrico Testa, one of the voices most representative of contemporary Italian poetry, published in the volume Cairn, in 2018.

Keywords: Translation; Enrico Testa; Italian Poetry.

\section{REFERÊNCIAS}

AGAMBEN, Giorgio. La fine del pensiero. La fin de la pensée. Trad. Gérard Macé. Paris: La Nouveau Commerce, 1982.

AGAMBEN, Giorgio. Ideia da prosa. Trad. e pref. João Barrento. Lisboa: Cotovia, 1999.

AGAMBEN, Giorgio. O fogo e o relato: ensaios sobre criação, escrita, arte e livros. Trad. Andrea Santurbano e Patricia Peterle. São Paulo: Boitempo, 2018.

BENJAMIN, Walter. A tarefa do tradutor. Trad. Susana Kapf Lages. In: HEIDERMANN, Werner (Org.). Clássicos da teoria da tradução. Florianópolis: UFSC - Núcleo de Pesquisas em Literatura e Tradução, 2010, pp. 202-231.

BENJAMIN, Walter. Rua de mão única. Trad. Rubens Rodrigues Torres Filho e José Carlos Martins Barbosa. São Paulo: Rafael Copetti Editor, 2017.

BENVENISTE, Émille. Problemas de Linguística Geral. Trad. Maria da Glória Novak e Luiza Neri. São Paulo: Companhia Editora Nacional/Editora da Universidade de São Paulo, 1976.

BERMAN, Antoine. A tradução e a letras ou o albergue do longínquo. Trad. Marie-Hélène Catherine Torres, Mauri Furlan e Andréia Guerini. Rio de Janeiro: 7Letras/PGET, 2007.

BONDİA, Jorge Larrosa. Notas sobre a experiência e o saber de experiência. Trad. João Wanderley Geraldi. Revista Brasileira de Educação, Rio de Janeiro, n. 19, abr. 2002, pp. 20-28. Disponível em: <http://www.scielo.br/pdf/rbedu/n19/n19ao2.pdf>. Acesso em: 10 abr. 2018.

CALVINO, Italo. Saggi 1945-1985. Org. Mario Barenghi. V. II. Milano: Mondadori, 1995.

CALVINO, Italo. Mondo scritto e mondo non scritto. Milano: Mondadori, 2002.

CAPRONI, Giorgio. A porta morgana: ensaios sobre poesia e tradução. Trad. Patricia Peterle, pref. Enrico Testa. São Paulo: Rafael Copetti Editor, 2017.

CASSIN, Barbara (org.). Vocabulaire européen des philosophies: dictionnaire desintraduisibles. Paris: Le Seuil, 2004.

CASSIN, Barbara. Éloge de la traduction: compliquer l'universel. Paris: Fayard, 2016. 
DANTE. A divina comédia. Trad. Cristiano Martins. V. I. Belo Horizonte: Villa Rica, 1991.

DELEUZE, Gilles. Crítica e clínica. Trad. Peter Pál Pelbart. São Paulo: Editora 34, 2011.

JACQUES, Marcelo. Sobre a forma, o poema e a tradução. Rio de Janeiro: 7 Letras, 2017.

LARKING, Philip. The Complete Poems. Introduction and Commentary by Archie Burnett. Nova York: Farrar, Straus and Giroux, 2012.

MENEGHELLO, Helena Coimbra. Italo Calvino: um ponto de vista sobre o papel da tradução literária. Dissertação (Mestrado em Estudos da Tradução) - Universidade Federal de Santa Catarina, 2011. Disponível em: <http://www.pget.ufsc.br/curso/ dissertacoes/Helena_Coimbra_Meneghello_-_Dissertacao.pdf $>$. Acesso em: 9 abr. 2018.

MENEGHELLO, Helena Coimbra. Italo Calvino e o intricado jogo da tradução. Tese (Doutorado em Estudos da Tradução) - Universidade Federal de Santa Catarina, 2016. Disponível em: <http://www.pget.ufsc.br/curso/teses/Helena_Coimbra_ Meneghello_-_Tese.pdf>. Acesso em: 9 abr. 2018.

NANCY, Jean-Luc. Demanda: literatura e filosofia. Trad. João Camillo Penna, Eclair Antonio Almeida Filho e Dirlenvalder do Nascimento Loyolla. Florianópolis/Chapecó: Ed. UFSC/Argos, 2016.

OLIVEIRA, Claudio. Da intraduzibilidade como política. Revista Cult (on-line), São Paulo, 20 dez. 2016. Disponível em: <https://revistacult.uol.com.br/home/ daintraduzibilidade-como-politica/>. Acesso em: 25 set. 2018.

PETERLE, Patricia. Em diálogo com Enrico Testa. Manuscrítica, São Paulo, n. 28, 2015, pp. 13-25. Disponível em: <http://revistas.fflch.usp.br/manuscritica/article/ view/2136/2146>. Acesso em: 14 set. 2018.

PETERLE, Patricia. Vagando qua e là. La poesia di Enrico Testa. Nuova Corrente, n. 16o, anno LXIV, 2017, pp. 125-132.

PETRY, Simone Christina. Éloge de la traduction: compliquer l'universel. Remate de Males, Campinas-SP, v. 37 n. 2, jul./dez. 2017, pp. 1.007-1.016. Disponível em: <https:// periodicos.sbu.unicamp.br/ojs/index.php/remate/article/view/8650447>. Acesso em: 14 set. 2018 .

PRIGENT, Christian. Para que poetas ainda? Org. e trad. Inês Oseki-Dépré e Marcelo Jacques de Moraes. Florianópolis: Cultura e Barbárie, 2017.

RICOEUR, Paul. Sobre tradução. Trad. Patrícia Lavalle. Belo Horizonte: Editora UGMG, 2011.

TESTA, Enrico. Ablativo. Trad. Patricia Peterle, Andrea Santurbano e Silvana de Gaspari. São Paulo: Rafael Copetti Editor, 2014a. 
TESTA, Enrico. Poesia aporética. [Entrevista a Patricia Peterle]. Subtrópicos, Florianópolis, n. 11, ago., 2014b, pp. 6-7.

TESTA, Enrico. Préface. In: LINDENBERG, Judith. Giorgio Caproni, poète-traducteur: le rôle de la traduction dans le processos créatif. Bruxelles: Peter Lang, 2014c.

TESTA, Enrico. A entrada do terceiro. Pessoa. Língua, poesia. In: PETERLE, Patricia; GASPARI, Silvana de (orgs.). Arquivos poéticos: desagregação e potencialidades do Novecento italiano. Rio de Janeiro: 7Letras, 2015, pp. 22-42.

TESTA, Enrico. Páscoa de neve. Trad. Patricia Peterle. São Paulo: Rafael Copetti Editor, 2016.

TESTA, Enrico. Cairn. Torino: Einaudi, 2018. 